\title{
Numerical Solution of the Frequency Equations for the Flexural Vibration of Cylindrical Rods
}

\author{
W. E. Tefft \\ (June 28, 1960)
}

\begin{abstract}
A numerical solution of Pickett's frequency equations for the flexural vibration of cylindrical rods, based on the three-dimensional differential equations of elasticity, has been obtained on the IBM 704 computer. The results are presented in the form of tables of correction factors to be applied to the thin rod approximation for the fundamental flexural resonance frequency and the first two overtones. These results provide an accurate means of calculating Young's modulus from the density, dimensions, and resonance frequencies of cylindrical rods having diameter-to-length ratios as high as 0.6.
\end{abstract}

\section{Introduction}

Improved experimental techniques recently have made it possible to determine the elastic properties of materials to a high degree of precision by dynamic resonance methods. Factors which have limited accurate measurements are: Convenient experimental techniques are not well developed theoretically, and conversely, techniques based on well analyzed theories are experimentally difficult. A recent experimental investigation [i] ${ }^{1}$ showed that Pickett's [2] approximate solution of the flexure problem, based on Goen's [3] solution of 'Timoshenko's [4] equations may be in error by a few percent. In a later paper, Pickett [5] gave an accurate set of frequency equations based on the three-dimensional differential equations of elasticity. The purpose of the present paper is to present the results of a numerical solution of these more accurate equations. These numerical solutions have put the accurate theory of flexural vibration of cylinders into a more usable form. Elimination of theoretical errors, for this particular problem, has thus been achieved.

\section{Background}

According to the elementary, one-dimensional theory, Young's modulus, $E$, may be computed from the flexural resonance frequency, $f$, of a cylinder of density $\rho$, length $l$, and diameter $d$, from the equation [3]

$$
E=\frac{64 \pi^{2} \rho l^{4} f_{n}^{2}}{m_{n}^{4} d^{2}}
$$

where $f_{n}$ is the resonance frequency of the $n^{\text {th }}$ mode of vibration and the $m_{n}$ are solutions of the equation $\cos m \cosh m=1$.

The values of $m_{n}$ for the first three modes of vibration are $[6]$

$$
\begin{aligned}
& m_{1}=4.730041, \\
& m_{2}=7.853205, \\
& m_{3}=10.995608 .
\end{aligned}
$$

\footnotetext{
Figures in brackets indicate the literature references at the end of this paper
}

Timoshenko [4] added shear and rotatory inertia corrections to the differential equation, and Goens [3] reduced the resulting frequency equation to the form

$$
E=\frac{64 \pi^{2} \rho l^{4} f_{n}^{2}}{m_{n}^{4} d^{2}} T_{n}
$$

where $T_{n}$ is a iunction of $d / l$ and Poisson's ratio, $\mu . T_{n}$ approaches one as $d / l$ approaches zero, for all values of $n$ and $\mu$.

Pickett [2] made numerical computations of the $T_{n}$, and gave approximate equations for this computation. These values are not as accurate as is desirable, in view of the experimental precision now attainable in dynamic resonance measurements. The basis for the more accurate values presented in this paper was given by Pickett [5] in his solution based upon the three-dimensional differential equations of elasticity.

A brief verbal sketch of Pickett's derivation may be helpíul in understanding the meaning of some of the following equations. He begins by noting that there are three fundamental solutions for elastic waves in a cylinder. Each is characterized by the angular frequency $p$ and the wavelength $2 \pi a / \gamma$, where $a$ is the radius of the cylinder. These three solutions can be combined so that their sum satisfies the boundary conditions on the curved suriace of the cylinder. This gives a relationship between $p$ and $\gamma$ expressed by Pickett's [5] equation 12. For each value of $p$ there are two values of $\gamma$, denoted by $\gamma$ and $\gamma^{\prime}$, which satisfy this equation. One of these, $\gamma^{\prime}$, corresponds to a sum which represents a traveling wave. The other, $\gamma$, corresponds to a sum in which the "wavelength" is an imaginary number, i.e., the displacement is an exponential, rather than a sinusoidal function of distance along the rod. Pickett combines both of these sums to get a solution for displacements which approximately satisfies the boundary conditions on the flat ends of the cylinder. These boundary conditions lead to his equation 21, the frequency condition. The present paper is concerned with the simultaneous numerical solution of these equations. 


\section{Theory and Calculations}

Pickett's [5] results were reduced to the form of equations (7) through (12) below, by a method similar to that used by Hudson [7]. Pickett's equation 12 is an expression of the requirement that the three radial components of stress be zero at the surface of the cylinder. This equation was reduced to the form of eq (7) by the aid of definition (10) and a suitable manipulation of the resulting determinant to reduce it from third order to second order.

$$
\begin{aligned}
& 2 K^{2} \psi(h)+\left(K^{2}-\gamma^{2}\right)\left[2 \psi(K)+K^{2}\right] \quad-2 \gamma^{2}\left[3 \psi(K)+K^{2}\right] \\
& 2 K^{2} \psi(h)+\left(K^{2}+\gamma^{2}\right) \quad\left(K^{2}-\gamma^{2}\right) \psi(K)+\left(K^{2}+\gamma^{2}\right. \text {, } \\
& =0 \text {, }
\end{aligned}
$$

where $h$ and $K$ are defined by

$$
\begin{aligned}
h & =\left[\frac{(1+\mu)(1-2 \mu)}{1-\mu} \frac{\rho a^{2} p^{2}}{E}-\gamma^{2}\right]^{\frac{1}{2}}, \\
K & =\left[2(1+\mu) \frac{\rho a^{2} p^{2}}{E}-\gamma^{2}\right]^{\frac{1}{2}},
\end{aligned}
$$

where

$\mu=$ Poisson's ratio,

$E=$ Young's modulus,

$\rho=$ density,

$a=d / 2, d$ being diameter of cylinder,

$p=2 \pi f=$ angular frequency of flexural vibration,

$\gamma=$ parameter determined from the solution of these equations,

$\psi=$ a combination of Bessel functions of the first kind, orders zero and one, and is defined by

$$
\begin{aligned}
\psi(X) & =\frac{X J_{o}(X)}{J_{1}(X)}-2 \\
& =-\frac{X^{2}}{4}\left[1+\frac{X^{2}}{24}+\frac{X^{4}}{384}+\frac{X^{6}}{5760}+\cdots\right]
\end{aligned}
$$

If we define the function

$$
\left.\begin{array}{rl}
F(\gamma)= & \frac{K^{2} \gamma}{\gamma^{2}+K^{2}}\left[\psi(h) K^{2}\left(\frac{K^{2}+\gamma^{2}}{2 h^{2}}-1\right)\right. \\
& \left.+\psi(K)\left(\frac{K^{2}-\gamma^{2}}{2}\right)+\psi h\right) \psi(K)\left(3 \frac{K^{2}+\gamma^{2}}{2 h^{2}}-2\right) \\
& \left.+\psi^{2}(K)\left(\frac{K^{2}-\gamma^{2}}{K^{2}}\right)\right]\left[K^{2} \psi(h)+\left(K^{2}+2 \gamma^{2}\right) \psi(K)\right. \\
& \left.+\frac{K^{2}}{2}\left(\gamma^{2}+K^{2}\right)\right]-1\left\{-\cot \frac{\gamma l}{2 a}\right. \\
\tan \frac{\gamma l}{2 a}
\end{array}\right\},
$$

where the upper terms in braces refer to the odd numbered and the lower terms to the even numbered modes of vibration, then equation 21 of [5] becomes

$$
F(\gamma)=F\left(\gamma^{\prime}\right)
$$

The problem of determining the flexural resonance frequencies is now solved in principle. For a given length, diameter, Young's modulus, and Poisson's ratio, one must solve (7) and (12) simultaneously for $p$ (and incidentally for $\gamma$ and $\gamma^{\prime}$ ). However, these are transcendental equations and involve the frequency in such a complex way that numerical methods must be used.

A program for obtaining a numerical solution of the simultaneous set of transcendental eqs (7) and (12), using (11), on the IBM 704 computer was written by the Bureau's computer section. The numerical solution was made in the manner suggested by Pickett [5]. Appropriate values of $\rho a^{2} p^{2} / E$ and $\mu$ were chosen. The two real values of $\gamma^{2}$ satisfying eq (7) were determined by successive approximations. These values of $\gamma^{2}$ were then substituted in eq (11) and the values of $l / 2 a$ satisfying eq (12) for each of the first three modes of vibration were determined by successive approximation. The correction factors, $T_{n}$, were then computed from the relation

$$
T_{n}=\frac{m_{n}^{4}\left(\frac{a}{l}\right)^{4}}{4 \frac{\rho a^{2} p^{2}}{E}} .
$$

Twenty-nine values of $\rho a^{2} p^{2} / E$ were chosen, ranging in value from $1.0 \times 10^{-6}$ to 0.3958 . For each of these values of $\rho a^{2} p^{2} / E$, eleven values of $\mu$ were chosen, ranging from zero to 0.50 in steps of 0.05 . There were thus 319 computed points for each of the first three modes of vibration.

The values of $T_{1}, T_{2}$, and $T_{3}$ were then computed for equal intervals of $2 a / l$ by a sixth-order Aitken's [8] interpolation method. The overall error in these computations was less than three parts in $10^{6}$ for values of $\rho a^{2} p^{2} / E$ greater than about 0.0007 , corresponding to $d / l \approx 0.1$ for the fundamental mode. For lower values of $\rho a^{2} p^{2} / E$, however, machine round-off error became significant. In order to obtain accurate values of $T$ for $\rho a^{2} p^{2} / E<0.0007$, which corresponds to long thin rods, it was necessary to make a first-order approximation to the set of eqs (7), (11), and (12). This was accomplished as follows:

If we let

$$
\frac{(1+\mu)(1-2 \mu)}{1-\mu}=A, \quad 2(1+\mu)=B, \text { and } \frac{\rho a^{2} p^{2}}{E}=P,
$$

then, from eqs. (8) and (9),

$$
h^{2}=A P-\gamma^{2}, \quad K^{2}=B P-\gamma^{2},
$$

and from eq (10) we obtain

$$
\begin{aligned}
\psi(h)=-\frac{A P-\gamma^{2}}{4}\left[1+\frac{A P-\gamma^{2}}{24}+\frac{\left(A P-\gamma^{2}\right)^{2}}{384}\right. & \\
+\frac{\left(A P-\gamma^{2}\right)^{3}}{5760}+. & \cdot \cdot]
\end{aligned}
$$


and

$$
\begin{aligned}
\psi(K)=-\frac{B P-\gamma^{2}}{4}[1+ & \frac{B P-\gamma^{2}}{24}+\frac{\left(B P-\gamma^{2}\right)^{2}}{384} \\
+\frac{\left(B P-\gamma^{2}\right)^{3}}{5760}+\cdots & \cdot \cdot]
\end{aligned}
$$

If eqs (14), (15), and (16) are substituted in eq (7), terms of order $\gamma^{2}$ cancel (terms of the form $\gamma^{2} \rho^{n}$ are higher order). Inspection of the lowest order terms present shows that

$$
\gamma^{2} \approx \pm 2 \sqrt{P}
$$

But obtaining a solution to (12) requires that the magnitude of $\gamma^{2}$ and $\gamma^{\prime 2}$ be different. We must, therefore, make a second-order approximation to eq (7). Also, it is obvious from eq (17) that $\gamma^{2}$ is of order $\sqrt{P}$, not of order $P$; therefore, we must keep the first three terms of (15) and (16) for this approximation. When this is done, and algebraic simplifications are made, we arrive at

$$
\gamma^{4}-4 P-\frac{2}{3}(5+2 \mu) P \gamma^{2}-\frac{\mu}{12(1+\mu)} \gamma^{6}=0,
$$

where the last two terms are of higher order than the first two. In order to solve (18) for the two real values of $\gamma^{2}$, assume

$$
\gamma^{2}=C \sqrt{P}+D P,
$$

where $C$ and $D$ are functions of $\mu$ to be determined. The substitution of (19) into (18) results in a polynomial in $\sqrt{P}$. If we neglect terms of order higher than $p^{3 / 2}$, and equate the coefficients of each of the remaining powers of $P$ separately to zero, we arrive at the following values for $C$ and $D$.

$$
C= \pm 2
$$

and

$$
D=\frac{10+15 \mu+4 \mu^{2}}{6(1+\mu)} .
$$

Therefore,

$$
\gamma^{\prime 2}=+2 \sqrt{\frac{\rho a^{2} p^{2}}{E}}+\left(\frac{10+15 \mu+4 \mu^{2}}{6(1+\mu)}\right)\left(\frac{\rho a^{2} p^{2}}{E}\right),
$$

and

$$
\gamma^{2}=-2 \sqrt{\frac{\rho a^{2} p^{2}}{E}}+\left(\frac{10+15 \mu+4 \mu^{2}}{6(1+\mu)}\right)\left(\frac{\rho a^{2} p^{2}}{E}\right) .
$$

Equations (20) and (21) were then substituted in (11) and (12), and the functions $\cot \gamma l / 2 a, \cot \gamma^{\prime} l / 2 a$, tan $\gamma l / 2 a$, and $\tan \gamma^{\prime} l / 2 a$ were approximated in the following manner: since $\gamma^{2}<0, \quad \gamma$ is imaginary, so the following relations hold identically:

$$
\cot \frac{\gamma l}{2 a}=-i \operatorname{coth} \frac{|\gamma| l}{2 a}
$$

and

$$
\tan \frac{\gamma l}{2 a}=i \tanh \frac{|\gamma| l}{2 a} .
$$

Furthermore, it is known from the elementary solution that

$$
\lim _{\frac{2 a}{l} \rightarrow 0} \cot \frac{\gamma^{\prime} l}{2 a}=\lim _{\substack{2 a \\ l} 0}\left(-\operatorname{coth} \frac{|\gamma| l}{2 a}\right)=\cot \frac{m}{2}
$$

for odd-numbered modes, and

$$
\lim _{\frac{2 a}{l} \rightarrow 0} \tan \frac{\gamma^{\prime} l}{2 a}=\lim _{\frac{2 a}{l} \rightarrow 0} \tanh \frac{|\gamma| l}{2 a}=\tan \frac{m}{2}
$$

for even-numbered modes. We therefore make a first-order Taylor's series expansion of these functions about the point $m / 2$, giving

$$
\cot \frac{\gamma^{\prime} l}{2 a} \approx \cot \frac{m}{2}-\frac{\frac{\gamma^{\prime} l}{2 a}-\frac{m}{2}}{\sin ^{2} \frac{m}{2}},
$$

and similar approximations for the other three functions.

The quantity $\rho a^{2} p^{2} / \mathrm{E}$ was eliminated by means of (13), and the various powers of $T$ which appeared were eliminated by means of a Taylor's series expansion about the point $d / l=0, T=1$. This expansion can be shown to contain no terms of order $d / l$, so the first correction term in the expansion is proportional to $(d / l)^{2}$.

With these substitutions and further algebraic and trigonometric manipulation, we arrive at the following equation

$$
\begin{array}{r}
T \approx 1+\left[\left(\frac{m^{2}(\sin m+\sinh m)}{\sinh m-\sin m}\right)\left(\frac{10+15 \mu+4 \mu^{2}}{48(1+\mu)}\right)\right. \\
\left. \pm\left(\frac{m \sin m \sinh m}{\sin m-\sinh m}\right)\left(\frac{2-3 \mu-4 \mu^{2}}{24(1+\mu)}\right)\right]\left(\frac{d}{l}\right)^{2},
\end{array}
$$

where the upper (plus) sign refers to odd-numbered modes and the lower (minus) sign refers to evennumbered modes of vibration.

Inserting the values of $m$ from eq (3), (4), and (5) we obtain

$$
\begin{aligned}
& T_{1} \approx 1+4.88669\left(\frac{1+1.26225 \mu+0.20980 \mu^{2}}{1+\mu}\right)\left(\frac{d}{l}\right)^{2}, \\
& T_{2} \approx 1+13.5234\left(\frac{1+1.35472 \mu+0.28377 \mu^{2}}{1+\mu}\right)\left(\frac{d}{l}\right)^{2}, \\
& T_{3} \approx 1+26.1028\left(\frac{1+1.39469 \mu+0.31575 \mu^{2}}{1+\mu}\right)\left(\frac{d}{l}\right)^{2} .
\end{aligned}
$$

A plot of $T$ versus $(d / l)^{2}$ is nearly a straight line. This indicates that the first term (of order $(d / l)^{2}$ ) in the Taylor's series expansion of $T$ gives most of the contribution over the range of interest. Thus, the function

$$
H=\frac{T-1}{\left(\frac{d}{l}\right)^{2}}
$$

varies only very slowly with $(d / l)^{2}$ 
The method for obtaining accurate values of $T$ in the region $(d / l)^{2}<<1$ is now apparent. A plot of $H$ versus $(d / l)^{2}$ is made on a highly expanded scale, for each of the first three modes of vibration and for each value of $\mu$, with the $H$ intercept being obtained in each case from the appropriate one of eq (22), (23), or (24) and the other points being taken from the computer solution. When plotted in this manner, the first few points from the computer solution did not form a smooth curve. This scattering of points was an indication of significant round-off error at these low values of $(d / l)^{2}$. These points were therefore ignored, and the smooth curve, obtained at higher values of $(d / l)^{2}$, was extended to the chosen intercept. Finally, the values of $H$ for equally spaced intervals of $(d / l)$ were read from this smoothed curve, and the values of $T$ were computed from eq (25).

\section{Results and Discussion}

Tables 1, 2, and 3 give $T$ as a function of $d / l$ and $\mu$, for the first, second, and third modes respectively. These tables are accurate to about three parts in $10^{6}$. In order to calculate Young's modulus from measurements of the flexural resonance frequencies of cylinders, the following equations, based on eq (6), are used:

$$
\begin{aligned}
& E=1.261886 \frac{\rho l^{4} f_{1}^{2}}{d^{2}} T_{1}, \\
& E=0.1660703 \frac{\rho l^{4} f_{2}^{2}}{d^{2}} T_{2},
\end{aligned}
$$

and

$$
E=0.04321184 \frac{\rho l^{4} f_{3}^{2}}{d^{2}} T_{3}
$$

for the first, second, and third modes respectively.

A linear interpolation of $T$ versus $(d / l)^{2}$ or $T$ versus $\mu$ can be made with an accurac $v$ of better than one part in $10^{4}$ over the range of the tables. To obtain higher accuracy, Aitken's interpolation method should be used.

In order to obtain maximum accuracy from this method of Young's modulus determination, it is recommended that, whenever feasible, resonance frequencies of the fundamental and first two overtones be measured, and the values of $E$ be computed for each. An average of these values of $E$ should be more accurate than any of them alone. The reason for this is that small irregularities in the diameter of a specimen, which can never be eliminated com pletely, will affect each mode differently; i.e., some modes will have their frequencies shifted upward, and some downward. The magnitude of the disagreement among these values of $E$ indicates the overall uniformity of the dimensions of the specimen.

The correctness of these computations was checked experimentally, by a method which will be described in a subsequent publication. Table 4 gives a comparison of experimental and theoretical values of $T$ for two of the most accurately machined specimens. The discrepancy between theory and experiment is seen to be of the order of 0.03 percent, except for $T_{3}$. The experimental value of $T_{3}$ was difficult to

TABLE 1. The correction factor for the fundamental mode of flexural vibration of cylinders, $T_{1}$, as a function of the diameter to length ratio, $d / l$, and Poisson's ratio, $\mu$.

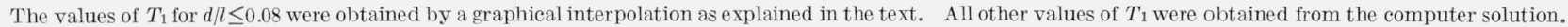

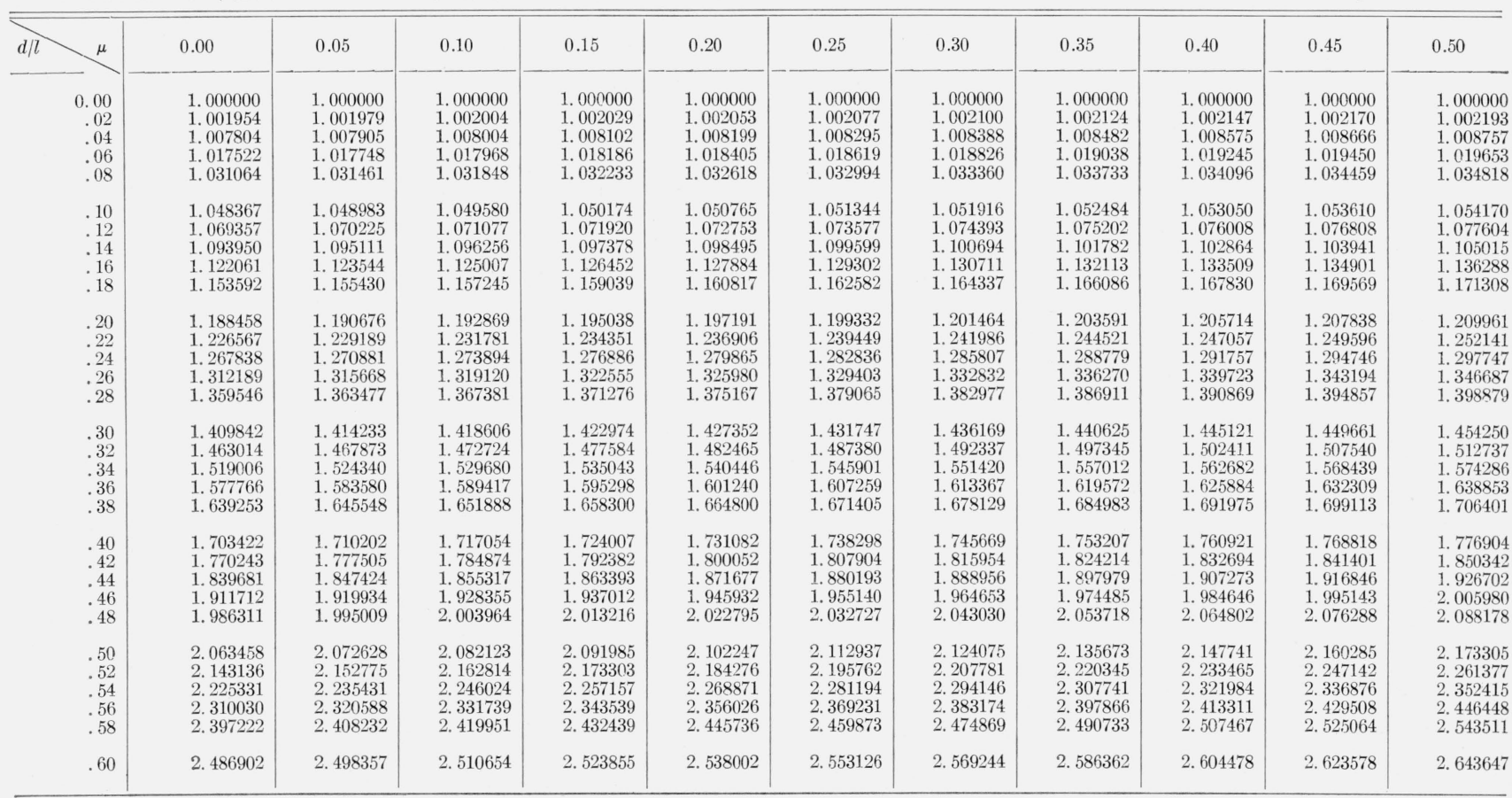


TABLE 2. The correction factor for the first overtone of flexural vibration of cylinders, $T_{2}$, as a function of the diameter to length ratio, d/l, and Posson's ratio, $\mu$.

The values of $T_{2}$ for $d / l \leq 0.05$ were obtained by a graphical interpolation, as explained in the text. All other values were obtained from the computer solution.

\begin{tabular}{|c|c|c|c|c|c|c|c|c|c|c|c|}
\hline$\mu$ & 0.00 & 0.05 & 0.10 & 0.15 & 0.20 & 0.25 & 0.30 & 0.35 & 0.40 & 0.45 & 0.50 \\
\hline 0.00 & 1.000000 & 1.000000 & 1.000000 & 1.000000 & 1.000000 & 1.000000 & 1.000000 & 1.000000 & 1.000000 & 1.000000 & 1.000000 \\
\hline .01 & 1. 001352 & 1.001376 & 1.001399 & 1.001422 & 1.001445 & 1.001467 & 1.001489 & 1.001511 & 1.001533 & 1.001554 & 1. 001576 \\
\hline .02 & 1.005404 & 1.005499 & 1.005592 & 1.005683 & 1.005774 & 1.005863 & 1.005952 & 1.006039 & 1.006126 & 1. 006212 & 1.006297 \\
\hline .03 & 1. 012144 & 1.012355 & 1.012564 & 1. 012770 & 1. 012973 & 1. 013174 & 1. 013373 & 1. 013569 & 1.013763 & 1. 013957 & 1.014149 \\
\hline .04 & 1.021552 & 1.021926 & 1.022295 & 1.022660 & 1.023019 & 1.023376 & 1. 023728 & 1.024077 & 1.024421 & 1. 024763 & 1.025103 \\
\hline .05 & 1.033605 & 1. 034188 & 1.034760 & 1. 035326 & 1. 035885 & 1.036440 & 1.036987 & 1.037530 & 1.038064 & 1. 038597 & 1. 039128 \\
\hline .06 & 1.048267 & 1.049105 & 1.049924 & 1.050734 & 1.051537 & 1.052327 & 1.053108 & 1.053883 & 1. 054653 & 1.055417 & 1. 056178 \\
\hline .07 & 1.065511 & 1.066641 & 1. 067750 & 1.068844 & 1. 069926 & 1.070995 & 1.072054 & 1. 073103 & 1.074146 & 1.075181 & 1. 076211 \\
\hline .08 & 1.085296 & 1.086759 & 1.088198 & 1.089613 & 1.091015 & 1.092401 & 1.093775 & 1.095137 & 1.096491 & 1. 097837 & 1. 099177 \\
\hline .09 & 1. 107583 & 1.109415 & 1. 111219 & 1.112996 & 1. 114756 & 1.116497 & 1.118223 & 1. 119937 & 1. 121641 & 1. 123337 & 1. 125025 \\
\hline .10 & 1.132330 & 1.134568 & 1. 136772 & 1.138949 & 1.141103 & 1. 143235 & 1.145352 & 1.147455 & 1.149547 & 1.151630 & 1. 153705 \\
\hline .11 & 1. 159496 & 1. 162177 & 1. 164820 & 1. 167429 & 1. 170012 & 1. 172573 & 1. 175115 & 1.177643 & 1. 180161 & 1.182668 & 1. 185170 \\
\hline .12 & 1. 189048 & 1. 192205 & 1. 195318 & 1. 198394 & 1. 201441 & 1.204465 & 1. 207470 & 1. 210461 & 1. 213439 & 1. 216410 & 1. 219376 \\
\hline .13 & 1. 220947 & 1.224613 & 1. 228230 & 1.231807 & 1. 235353 & 1. 238874 & 1. 242376 & 1. 245865 & 1. 249343 & 1. 252816 & 1. 256285 \\
\hline .14 & 1. 255166 & 1. 259371 & 1. 263523 & 1.267633 & 1. 271711 & 1. 275764 & 1. 279800 & 1. 283822 & 1. 287838 & 1. 291851 & 1. 295863 \\
\hline .15 & 1. 291674 & 1. 296449 & 1. 301168 & 1. 305844 & 1. 310487 & 1.315106 & 1. 319710 & 1. 324305 & 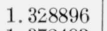 & 1. 333488 & 1. 338084 \\
\hline .16 & 1. 330448 & 1. 335824 & 1. 341140 & 1. 346414 & 1. 351656 & 1. 356876 & 1. 362084 & 1. 367288 & 1. 372493 & 1.377705 & 1. 382928 \\
\hline .17 & 1. 371471 & 1. 377477 & 1. 383422 & 1. 389325 & 1. 395199 & 1. 401055 & 1. 406905 & 1. 412756 & 1. 418616 & 1. 424490 & 1. 430382 \\
\hline .18 & 1. 414728 & 1. 421393 & 1. 427999 & 1. 434563 & 1. 441104 & 1. 447633 & 1. 454162 & 1. 460700 & 1. 467255 & 1. 473834 & 1. 480442 \\
\hline .19 & 1. 460212 & 1. 467565 & 1. 474861 & 1. 482122 & 1. 489364 & 1. 496602 & 1. 503850 & 1. 511116 & 1. 518411 & 1. 525741 & 1. 533111 \\
\hline .20 & 1. 507918 & 1. 515991 & 1. 524010 & 1. 532000 & 1. 539980 & 1. 547966 & 1. 555973 & 1. 564010 & 1. 572090 & 1. 580217 & 1. 588400 \\
\hline .21 & 1. 557849 & 1. 566672 & 1.575448 & 1. 584202 & 1. 592958 & 1. 601732 & 1. 610540 & 1. 619395 & 1. 628306 & 1. 637282 & 1. 646330 \\
\hline .22 & 1. 610014 & 1. 619619 & 1. 629185 & 1. 638741 & 1. 648312 & 1. 657917 & 1. 667572 & 1. 677290 & 1. 687084 & 1. 696961 & 1. 706930 \\
\hline .23 & 1. 664427 & 1. 674847 & 1. 685239 & 1. 695636 & 1. 706063 & 1. 716543 & 1. 727092 & 1. 737726 & 1. 748455 & 1.759290 & 1. 770238 \\
\hline .24 & 1. 721106 & 1. 732377 & 1. 743634 & 1. 754912 & 1. 766240 & 1. 777642 & 1. 789136 & 1. 800738 & 1. 812460 & 1.824312 & 1. 836303 \\
\hline .25 & 1. 780080 & 1. 792238 & 1.804400 & 1.816603 & 1. 828880 & 1.841254 & 1.853748 & 1.866375 & 1. 879151 & 1.892085 & 1. 905185 \\
\hline .26 & 1. 841381 & 1.854465 & 1. 867575 & 1.880751 & 1. 894027 & 1. 907428 & 1. 920979 & 1. 934694 & 1. 948588 & 1. 962672 & 1. 976953 \\
\hline .27 & 1. 905048 & 1. 919102 & 1. 933207 & 1.947405 & 1. 961734 & 1. 976222 & 1. 990892 & 2.005761 & 2. 020844 & 2.036152 & 2. 051692 \\
\hline .28 & 1. 971129 & 1. 986199 & 2. 001348 & 2. 016625 & 2. 032066 & 2.047703 & 2.063560 & 2.079655 & 2. 096003 & 2.112614 & 2. 129495 \\
\hline .29 & 2.039679 & 2.055815 & 2.072063 & 2. 088477 & 2.105095 & 2.121950 & 2.139068 & 2.156467 & 2. 174161 & 2.192161 & 2.210474 \\
\hline .30 & 2. 110759 & 2. 128016 & 2.145425 & 2.163041 & 2.180906 & 2.199055 & 2. 217513 & 2.236300 & 2. 255430 & 2. 274913 & 2. 294753 \\
\hline .31 & 2. 184442 & 2. 202881 & 2. 221516 & 2.240405 & 2.259595 & 2. 279119 & 2. 299006 & 2.319274 & 2. 339937 & 2.361003 & 2. 382477 \\
\hline .32 & 2. 260809 & 2. 280496 & 2. 300430 & 2. 320672 & 2.341270 & 2. 362262 & 2. 383673 & $2.4055\llcorner 3$ & 2. 427824 & 2.450585 & 2.473806 \\
\hline .33 & 2. 339949 & 2. 360959 & 2. 382273 & 2. 403955 & 2. 426056 & 2. 448613 & 2. 471654 & 2. 495197 & 2. 519253 & 2. 543828 & 2.568923 \\
\hline .34 & 2. 421965 & 2. 444380 & 2. 467163 & 2. 490383 & 2.514090 & 2. 538324 & 2.563111 & 2.588468 & 2. 614407 & 2. 640929 & 2. 668033 \\
\hline .35 & 2. 506968 & 2. 530881 & 2. 555234 & 2. 580098 & 2. 605527 & 2. 631559 & 2. 658220 & 2. 685528 & 2. 713488 & 2. 742103 & 2. 771366 \\
\hline .36 & 2.595085 & 2. 620598 & 2. 646633 & 2. 673262 & 2. 700540 & 2.728506 & 2.757184 & 2. 786589 & 2.816726 & 2.847593 & 2.879180 \\
\hline
\end{tabular}

TABLE 3. The correction factor for the second overtone of flexural vibration, $\mathrm{T}_{3}$, as a function of the diameter to lencth rotio, d/l, and Poisson's ratio, $\mu$.

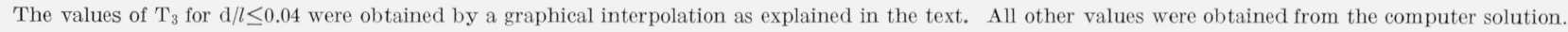

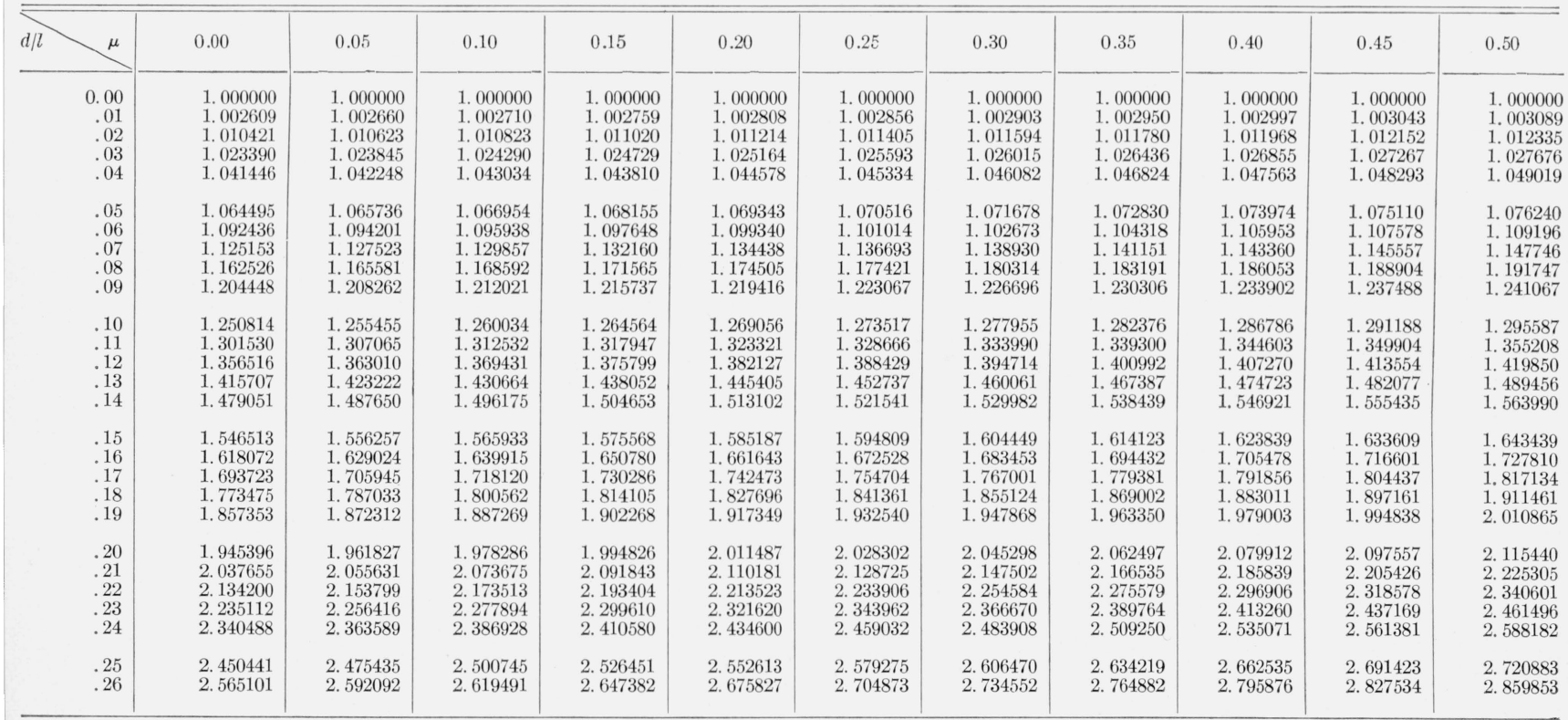


TABle 4. A comparison of theoretical and experimental values of the correction factors $\mathrm{T}_{1}, \mathrm{~T}_{2}$, and $\mathrm{T}_{3}$ for the first 3 modes of flexural vibration of cylinders

\begin{tabular}{|c|c|c|c|c|}
\hline & & Theoretica] & $\begin{array}{l}\text { Experi- } \\
\text { mental }\end{array}$ & $\begin{array}{c}\text { Percent } \\
\text { difference }\end{array}$ \\
\hline Specimen $A, d / l=0.27871 \ldots$ & $\begin{array}{l}T_{1} \\
T_{2} \\
T_{3}\end{array}$ & $\begin{array}{l}\text { 1. } 3787 \\
\text { 2. } 0503 \\
2.9814\end{array}$ & $\begin{array}{l}1.3790 \\
2.0498 \\
2.9770\end{array}$ & $\begin{array}{r}-0.02 \\
+.02 \\
-.15\end{array}$ \\
\hline Specimen $B, d / l=0.45039 \ldots$ & $T_{1}$ & 1. 9257 & 1.9251 & +.03 \\
\hline
\end{tabular}

The specimens were cut from a single bar of soft steel, and had a value of Poisson's ratio of 0.2879 .

obtain and is probably in error by a larger amount than the other values. Also, it was necessary to extrapolate beyond the range of the tables to obtain this theoretical value. In spite of this, the indicated error is only 0.15 percent.

We may conclude from this evidence that no significant disagreement with experiment can be detected by the use of presently available techniques. It is therefore believed that the estimate of error given herein is realistic, not only with regard to the errors in the numerical computations, but also with regard to the equations used.

The author expresses his appreciation to Irene Stegun and Ruth Zucker for writing the IBM 704 computer program used in these computations.

\section{References}

[1] S. Spinner, T. W. Reichard, and W. E. Tefft, A comparison of experimental and theoretical relations between Young's modulus and the flexural and longitudinal resonance frequencies of uniform bars, J. Research NBS 64A, 147 (1960).

[2] Gerald Pickett, Equations for computing elastic constants from flexural and torsional resonant frequencies of vibration of prisms and cylinders, ASTM Proc. 45, 846 (1945).

[3] E. Goens, Úber die Bestimmung des Elastizitäts moduls von Stäben mit Hilfe von Biegungs schwingungen, Ann. Physik (B. Folge) 11, 649 (1931).

[4] S. Timoshenko, Vibration Problems in Engineering, 2d Ed., p. 337, (D. Van Nostrand Co., New York, N.Y., 1937).

[5] Gerald Pickett, Flexural vibration of unrestrained cylinders and disks, J. Appl. Phys. 16, 821 (1945).

[6] Lord Rayleigh, The Theory of Sound, Dover Publications, Vol. 1, 278 (1945).

[7] G. E. Hudson, Dispersion of elastic waves in solid circular cylinders, Phys. Rev. 63, 46 (1943).

[8] A. C. Aitken, Proc. Edinburgh Math. Soc. [2] 3, 56 (1932).

(Paper 64B4-39) 


\title{
Publications of the National Bureau of Standards ${ }^{\star}$
}

\author{
(Including papers in outside journals)
}

Infrared spectrum of hydrobromic acid, E. K. Plyler, J. Research NBS 64A, No. 5, 37\% (1960).

A precise measurement of the infrared fundamental bands of $\mathrm{HBr}^{79}$ and $\mathrm{HBr}^{81}$ has been made. The two band centers have been found to be 2558.94 and $2558.56 \mathrm{~cm}^{-1}$, respectively. Rotational and vibrational constants have been calculated from the observed data. The constants are in good agreement with previous reported values. The centers of the two harmonic bands were used to calculate $\omega_{e} x_{e}$ and $\omega_{e} y_{e}$ and they were found to be 45.58 and $0.072 \mathrm{~cm}^{-1}$, respectively for $\mathrm{HBr}^{79}$ and 45.56 and $0.072 \mathrm{~cm}^{-1}$ for $\mathrm{HBr}^{81}$.

The spectrum of singly ionized atomic iodine (I II), W. C. Martin and C. H. Corliss, J. Research NBS 64A, No. 6, 443 (1960).

The I II spectrum has been excited in electrodeless lamps and photographed from 655 to $11084 \mathrm{~A}$. Wavelengths and estimated intensities are given for almost 2400 lines. A revision and extension of the earlier analyses of this spectrum has increased the number of known even levels from 43 to 124 , and the number of odd levels from 55 to 190 . New gJ-factors are given for 46 levels, and the previous designations of 40 levels are changed. Improved measurements in the vacuum ultraviolet region given a correction of $7.4 \mathrm{~cm}^{-1}$ to be subtracted from the values of all higher levels listed in Atomic Energy Levels, Vol. 3, (1958). The approximately 1800 classified lines now include all of the strongest lines. The ${ }^{1} \mathrm{~S}_{0}$ of the ground configuration $5 s^{2} 5 p^{4}$ has been found, and this configuration has been fitted to intermediate coupling theory. Magnetic dipole transitions between levels of the ground configuration, ${ }^{3} \mathrm{P}_{2}-{ }^{1} \mathrm{D}_{2}(7282 \mathrm{~A})$ and ${ }^{3} \mathrm{P}_{1}-{ }^{1} \mathrm{~S}_{0}$ $(4460 \mathrm{~A})$, have been observed and their nature confirmed by the Zeeman effect. The line $5 p^{4}{ }^{3} P_{2}-1 D_{2}$ shows hyperfine structure which is in approximate agreement with a theoretical calculation of the expected structure. New levels have been found for almost all higher configurations. All previously known series have been extended and new ones found. From one of the new series, $5 p^{3}\left({ }^{4} \mathrm{~S}^{\circ}\right) 5-12 g{ }^{5} \mathrm{G}_{6}^{\circ}$ the principal ionization energy for I II $\left(154304 \pm 1, \mathrm{~cm}^{-1}\right)$ has been derived. The results of the analysis are compared with theoretical expectations in a number of cases.

The third spectrum of gold (Au III), L. Iglesias, J. Research NBS 64A, No. 6, 481 (1960).

The spark spectrum of gold has been photographed in a helium atmosphere from 500 to $6600 \mathrm{~A}$. About 500 lines have been assigned to the third spectrum, Au III, and separated from those belonging to other stages of ionization, by observation of the polarity of the lines. Sixty two levels have been found: 17 even levels, arising from the $5 d^{9}$ and $5 d^{8} 6 s$ configurations; and 45 odd levels, belonging to the $5 d^{8} \quad 6 p$ and $5 d^{7} 6 s \quad 6 p$ configurations. All of the expected levels from the configurations $5 d^{9}, 5 d^{8} 6 s$ and $5 d^{8} 6 p$ have been identified except for the very high terms based on the $5 d^{8}\left({ }^{1} \mathrm{~S}\right)$ core of $\mathrm{Au}$ Iv. With these levels it was possible to classify 256 lines.

Note on particle velocity in collisions between liquid drops and solids, O. G. Engel, J. Research NBS 64A, No. 6, 497 (1960). Equations are developed for plane-wave particle velocity produced in solid-against-liquid collisions. An explicit expression for the dimensionless coefficient $\alpha$ that appears in these equations is deduced.

Error analysis of a standard microwave phase shifter, G. E. Schafer and R. W. Beatty, J. Research NBS 64C, No. 4, 261 (1960)

A standard microwave phase shifter has been proposed which utilizes an adjustable short circuit attached to a tunable three-arm waveguide junction. Two classes of errors considered are those due to imperfect tuning of the waveguide junction and those due to inaccuracies in determining the motion of the adjustable short circuit and the width of the waveguide, termed tuning and dimensional errors, respectively. Graphs are presented for estimating the scattering coefficient magnitudes needed to estimate limits of tuning error from observations of amplitude changes during the tuning procedure. Graphs are presented for estimating limits of dimensional error for WR-90 waveguide in the recommended frequency range of 8.2 to $12.4 \mathrm{kMc} / \mathrm{s}$ from tolerances of the axial motion of the short circuit and broad dimensions of the waveguide.

Electron resistivity studies on the Athabasca Glacier, Alberta, Canada, G. V. Keller and F. C. Frischknecht, J. Research NBS 64D, No. 5, 439 (1960).

The use of electrical methods for measuring ice thickness and properties on the Athabasca Glacier, Alberta, Canada, has been studied by the U.S. Geological Survey. Two methods for measuring resistivity were tried: one, a conventional resistivity method in which current was introduced galvanically into the glacier through electrodes, and the other an electromagnetic method in which a wire loop laid on the ice was used to induce current flow. Results of the galvanic measurements showed large variations in the resistivity of the ice; in a surface layer several tens of feet thick the resistivity is between 0.3 and 1.0 megohm-meters, and under this layer, the resistivity of the ice is more than 10 megohmmeters. The resistivity of the surface ice is determined by its water content rather than by molecular resonance loss. The ice had no effect on the mutual coupling measurements in the frequency range from 100 to 10,000 cycles per second. As a consequence the electromagnetic data could be interpreted simply in terms of ice thickness and bedrock resistivity.

Amplitude distribution for radio signals reflected by meteor trails, A. D. Wheelon, J. Research NBS 64D, No. 5,449 (1960). The probability distribution for the envelope of the received signal composed of reflections from many meteor trails is derived theoretically. Both the effects of numerous, small meteors and the residual reflections from infrequent, large meteors are treated simultaneously. For the particular example of exponential decay of initial spikes which are themselves distributed as the inverse square of their amplitudes, we find that the probability that the composite residual signal amplitude exceeds a prescribed level $r$ is given by

$$
P(R>r)=\frac{1}{\left[1+\frac{r^{2}}{(v \eta Q)^{2}}\right]^{1 / 2}} .
$$

This function behaves as a Rayleigh distribution for small amplitude margins $r$. For the larger, less likely amplitudes it agrees with the result predicted by elementary analysis of isolated meteor reflections. Possible refinements of these results are also discussed.

Computation and measurement of the fading rate of moonreflected UHF signals, S. J. Fricker, R. P. Ingalls, W. C. Mason, M. L. Stone, and D. W. Swift, J. Research NBS 64D, No. $5,455(1960)$.

A method is described for predicting the fast fading rate of moon-reflected signals. It is based entirely upon considerations of the observer-moon positions and relative motions. Experimental results which are in good agreement with the computed fading rates have been obtained from a moonreflection experiment at a frequency of $412 \mathrm{Mc} / \mathrm{s}$. Some possible implications of this method of interpreting fading rates are given. 
On the theory of wave propagation through a concentrically stratified troposphere with a smooth profile, H. Bremmer, $J$. Research NBS 64D, No. 5, 467 (1960).

The W.K.B. approximation for the solution of the heightgain differential equation for a curved stratified troposphere is discussed in detail. The approximation depends mainly on a variable $u_{l}(r)$ which can be interpreted as the height dependent contribution of the phase for a field solution obtained by separation of variables. An expansion of $u_{l}(r)$ with the aid of partial integrations leads to further approximations which facilitate the determination of the eigen values, and of the amplitudes of the modes connected with the propagation problem. The influence of the refractive-index profile, if assumed as smooth, then appears to be restricted to a dependence on the surface values of this index and of its gradient insofar as propagation over the ground is concerned. Further, all height effects of elevated antennas can be expressed in terms of the distance to the corresponding radio horizon. This results in simple relations between the fields connected with two different refractive-index profiles, provided both profile coincide near the earth's surface.

Polarization and depression-angle dependence of radar terrain return, I. Katz and L. M. Spetner, J. Research NBS 64D, No. 5, 483 (1960).

A study of recent experimental results on radar back scattering from land and sea surfaces indicate: (a) the polarization dependence of the normalized radar cross section, $\sigma_{0}$, of ocean surfaces cannot be explained by the usual "interference phenomenon" and (b) there is a distinct difference in the form of the depression-angle dependence in that $\sigma_{0}$ for "smooth" surfaces follows a negative exponential whereas $\sigma_{0}$ for "rough" surfaces drop off as the sine of the depression angle.

Methods of predicting the atmospheric bending of radio rays, B. R. Bean, G. D. Thayer, and B. A. Cahoon, J. Research NBS 64D, No. 5, 487 (1960).

Three methods for predicting the bending of radio rays when the refractive index profile above the surface layer is unknown have been developed recently by the authors. These methods are: a statistical technique for refraction at high initial elevation angles, estimation of bending from an exponential model of atmospheric refractive index, and a modification of the exponential model to account for the heavily weighted effects of anomalous initial refractive index gradients at small initial elevation angles. Each model is dependent upon the value of the refractive index at ground level or, in the case of superrefraction, the additional knowledge of the refractive index gradient next to the earth's surface. Each method works best in a particular range of initial elevation angles or meteorological conditions. The height and angular ranges of application of each method are checked by comparison with values obtained from 77 diverse refractive index profiles representative of wide climatic variation. It is found that the use of the best of the three methods will alwavs result in a prediction of the total atmospheric bending within 10 percent for initial elevation angles from zero to $10 \mathrm{mr}$ and to within 4 percent for initial elevation angles greater than 17 $\mathrm{mr}(\sim 1$ degree $)$

Use of logarithmic frequency spacing in ionogram analysis, G. A. M. King, J. Research NBS 64D, No. 5, 501 (1.960).

The use of logarithmic frequency spacing in the reduction of ionograms to electron density profiles brings several advantages. Among them is the fact that, when computing factors for the analysis, one need not determine the group refractive index. Formulae involving only the phase refractive index are presented; for the ordinary component one exact and one approximate formula are given, while for the extraordinary component there is an approximate formula . . . valid over a wide range of geomagnetic latitudes. There is a brief discussion of quasi-longitudinal approximations to the extraordinary phase refractive index.

Guiding of whistlers in a homogeneous medium, R. L. Smith, $J$. Research NBS 64D, No. 5, 505 (1960).

The velocity of energy flow of whistlers in a homogeneous medium is computed as a function of wave-normal angles. The maximum allowable cone of ray angles approaches $19^{\circ} 29^{\prime}$ at very low frequencies, decreases with frequency to a minimum of $11^{\circ}$ at a wave frequency of one-fifth the gyrofrequency, then increases to $90^{\circ}$ at the gyrofrequency. The velocity of energy flow departs markedly from the longitudinal value except at very low frequencies or very small wave-normal angles.

Shielding of transient electromagnetic signals by a thin conducting sheet, N. R. Zitron, J. Research NBS 64D, No. 5, 563 (1960).

The shielding effect of a thin, horizontal imperfectly conducting sheet against the transient field of a vertical magnetic dipole when excited by a ramp function is investigated. The results are calculated by taking Laplace transforms of the frequency spectrum functions for the steady-state problem. The response to the ramp function is calculated and the significance of the results in shielding against surges is discussed.

Cylindrical antenna theory, R. H. Duncan and F. A. Hinchey, $J$. Research NBS 64D, No. 5, 569 (1960).

A partial survey of cylindrical antenna theory pertaining to a tubular model with a narrow gap is presented. The survey includes discussion of the theories of Hallén, King and Middleton, Storm, and Zuhrt. A conceptual relation between theory and experiment is described. The latter part of the article is concerned with a new Fourier series solution of the Hallén equation. This solution is developed in such a way that the expansion coefficients are the unknowns of a system of linear equations. The elements of the coefficient matrix are given by a highly convergent series. Numerical results are given for half and full wavelength antennas with half length to radius ratios of 60 and 500. These results compare quite closely with those obtained from King-Middleton theory.

Vibration-rotation structure in absorption bands for the calibration of spectrometers from 2 to 16 microns, E. K. Plyler, A. Danti, L. R. Blaine, and E. D. Tidwell, NBS Mono 16 (1960) 20 cents.

Suitable bands of common gases have been tabulated and remeasured wherever necessary from 2 to 16 microns to obtain an accuracy of about $0.03 \mathrm{~cm}^{-1}$ throughout the region and to provide good calibrating points at frequent intervals. Some 600 rotation-vibration lines are illustrated in 20 spectrograms and wavenumbers are listed in companion tables with considerable intercomparison with worthy data obtained in other laboratories. The absorption bands were remeasured or calibrated by using either a precisely graduated grating circle or standard atomic lines with the fringe system formed by a Fabry-Perot interferometer. Characteristic features of the individual bands are discussed briefly and references to other publications are given. The substances used for calibration include $\mathrm{H}_{2} \mathrm{O}, \mathrm{CO}_{2}, \mathrm{CO}, \mathrm{HCl}, \mathrm{HBr}, \mathrm{NH}_{3}, \mathrm{C}_{2} \mathrm{H}_{2}$, $\mathrm{CH}_{4}, \mathrm{~N}_{2} \mathrm{O}$, and polystyrene film. (Reprinted from the Journal of Research of the National Bureau of Standards-A. Physics and Chemistry, Vol. 64A, No. 1, January-February 1960.

Dynamic measurements of the magnetoelastic properties of ferrites, V. E. Bottom, NBS Tech. Note 49 (PB151408) (1960) $\$ 1.00$

The relations between the mechanical and magnetic properties of a ferrite are derived for the small signal or reversible condition using thermodynamic principles. The equation of motion of a ferrite ring driven in its fundamental mode is set up and solved leading to the equivalent electrical circuit of the magnetostriction resonator. From mechanical measurements of the density and dimensions of the ring and electrical and frequency measurements of the resonator, the elastic modulus, permeability, magnetostriction coefficients and loss factors in the ferrite can be determined. Apparatus is proposed for performing the above measurements.

Magnetic drum directory and programming system for codesorting letter mail, P. C. Tosini, NBS Tech. Note 50 $(P B 151409) \quad(1960) \$ 1.75$.

This report is an analysis and extension of the Rabinow Engineering Company's proposal for a magnetic drum filedirectory and special purpose computer to be used in a test coded-address ("codesorting") letter-mail sorting system 
scheduled for late 1960 installation at the Washington, D.C Post Office. The report is composed of 6 major sections that successively examine the major considerations involved. A short introduction is presented first. Then the general problem of coding the fields composing addresses is discussed. This area is analyzed in terms of facilitating both the human coding process and the computer coded address-to-binnumber translation. Addresses are classified into two types: "standard" and "non-standard". When coded, their fields must be unique and yet be sufficiently flexible to specify a variety of addresses. They must furthermore adequately specify some more common forms of misaddressed mail that is presently correctly sorted manually. A slightly amended form of Coding Plan E-1 is then presented and analyzed in terms of the conditions specified for coded addresses in general.

After the presentation of the coding area, the local mail sort translation program of the Rabinow proposal is discussed in detail. It is then extended to include the outgoing mail translation program and non-standard and special address forms. The information and instruction characters necessitated by the programs are listed in detail and the effects of the file-directory source document preparation determined. A coding keyboard is then suggested.

The programming is then reexamined and it is determined that all addresses can be treated as special cases of the standard address forms at an increased cost in memory space and with a saving in the special instruction symbols required Finally, alternative methods of file-directory information storage are explored and evaluated in terms of memory space requirements, table look-up and directory access times, and conceptual simplicity.

Carrier frequency dependence of the basic transmission loss in tropospheric forward scatter propagation, K. A. Norton, NBS Tech. Note 53 (PB161554) (1960)\$1.00.

A further interpretation is given of certain Lincoln Laboratory data obtained in an experiment using scaled antennas as presented in a recent letter to the Proceedings of the I.R.E. from Bolgiano. This paper has four objectives: first, to clarify the significance of these data from the standpoint of the engineer developing long-range tropospheric scatter systems; second, to apply a further statistical analysis to these data; third, to consider their significance as regards the theory of radio propagation through a turbulent atmosphere; and fourth, to describe a suitable method for the measurement of the meteorological parameters entering the theory. Based on this analysis of the Lincoln Laboratory data, it is concluded that the carrier frequency dependence of the basic transmission loss cannot be variable from hour to hour.

Determination of a general index of effort in sorting mail by conventional methods, S. Henig, NBS Tech. Note 54 (PB161555) (1960) 50 cents.

The conventional method of sorting letters in stages is described. It is shown, through reference to available statistics, that about $90 \%$ of letters originating within the areas served by several large post offices will be involved in no more than five stages to be completely sorted to a carrier, firm or section of boxes. A method is presented for the accounting of each stage's individual letter readings which are defined as the units of measurement for the index of sorting effort. It is found that the upper bound average number of readings per letter for three large post offices varies from 3.16 to 2.98 and that these bounds are applicable to 96.2 to $92.4 \%$ of the local originating first class letters. It is anticipated that the values of such indexes for all large post offices will be consistently close to the range already determined.

Emission spectra of $\mathrm{N}_{2}, \mathrm{O}_{2}$, and $\mathrm{NO}$ molecules trapped in solid matrices, H. P. Broida and M. Peyron, J. Chem. Phys. 32, No. 4, 1068 (1960)

Molecular systems are observed in emission in solid products from a gas discharge trapped at liquid helium temperature. Previous tentative molecular assignments have been checked with the help of isotopic substitutions of oxygen and nitrogen. The Herzberg system ( $A$ bands) of oxygen $\left(A^{3} \Sigma_{u}^{+}-X^{3} \Sigma_{g}^{-}\right)$ is analyzed and the molecular constants are derived for a molecule trapped in a nitrogen matrix. Another system ( $M$ bands) is attributed to the NO molecule ( $\left.{ }^{4} \mathrm{II}-X^{2} \mathrm{II}\right)$.
The components of power appearing in the harmonic analysis of a stationary process, M. M. Siddiqui, presented at Symp. on Statistical Methods in Radio Wave Propagation, University of California, Los Angeles, June 18-20, 1958. Reprinted from "Statistical Methods in Radio Wave Propagation," (Pergamon Press, New York, N.Y., 1960).

Suppose that from a continuous record of a stationary process over a time interval $T$ seconds, $2 n+1$ equally spaced readings are taken and the usual harmonic analysis is performed. Assuming the true frequencies present in the process to be $1 /(3 T), 1 /(2 T), 1 / T, 2 / T$,

cycles per second, it is shown that the power ascribed to the frequency $j / T \mathrm{c} / \mathrm{s}$ consists of three components: (1) the true power in the frequency $j / T \mathrm{c} / \mathrm{s} ;(2)$ the powers in the frequencies $(2 k n \pm j) /$ $T \mathrm{c} / \mathrm{s}, k=1,2, \ldots ;(3)$ a part of the powers in the frequencies $1 /(m T) \mathrm{c} / \mathrm{s}, m=2,3$,

Introduction-Can you measure it? L. V. Judson, Am. Soc. Tool \& Mfgr. Engrs. Tech. Paper 239, Book 1, 60, 1 (1960). A paper which is the introductory paper in a Metrology Symposium. It indicates the need for precise and exact measurements and it treats two subsidiary questions: (1) Why measure? and (2) What has been the history of measurement?

Correction for systematic wavelength shift in atomic beam devices, R. L. Barger and K. G. Kessler, J. Opt. Soc. Am. 50, No. 4, 352 (1960).

Light emitted or absorbed by atoms in an atomic beam is shifted in frequency relative to the frequency for a stationary atom if the light ray is not normal to the trajectory of the atom. The magnitude of this shift is calculated and several devices which correct for this effect are described. For photoelectric recording of interference fringes, complete compensation can be achieved. In the case of photographic recording, it is shown that the residual error is negligible.

The error in prediction of $F \mathbf{2}$ maximum usable frequencies by world maps based on sunspot number, E. L. Crow and D. H. Zacharisen, Section II, Radio Propagation Phenomenology, book, Statistical methods in radio wave propagation, $p .248$ (Pergamon Press, New York, N. Y., 1960).

The feasibility of preparing semi-permanent world maps for predicting F2 maximum usable frequencies based on sunspot number is studied. The components of variance of the prediction are estimated; they arise from the following four major sources of error: determining regressions of $F 2$ characteristics on sunspot number with limited years of data, the scatter of points about these regressions, drawing world contour maps with limited numbers of stations, predicting the future sunspot number. All four sources are found to contribute about equally to a total standard deviation of monthly median maximum usable frequency predicted five months in advance of about 1 and $3 \mathrm{Me}$ for 0 and $4000 \mathrm{~km}$ respectively. Hence the proposed maps are concluded to be feasible.

Bremsstrahlung linear polarization, J. W. Motz and R. C. Placious, Il Nuovo Cimento 15, Series X, 571 (1960).

This work presents a general quantitative descrption of the bremsstrahlung linear polarization on the basis of original experimental data and available theoretical calculations. The results give the dependence of the polarization on $a$ ) the initial electron kinetic energy, $T_{0}$ in a range from $10^{-2}$ to $\left.10^{3} \mathrm{MeV}, b\right)$ the photon energy in a range from $0.1 T_{0}$ to $T_{0}$, c) the photon emission angle in a range from 0 to 180 degrees, and $d$ ) the atomic number of the target in a range from 4 to 79. The experimental data were obtained for a range of electron energies from 0.05 to $1.0 \mathrm{MeV}$ with beryllium, aluminum, and gold targets. Theoretical estimates of the polarization were calculated from the Sommerfeld-Kirkpatrick-Wiedmann results for the non-relativistic energy region, the Olsen-Maximon results for the extreme relativistic energy region, and the Gluckstern-Hull (Born approximation) results for the intermediate energy region. Final results are expressed in terms of the peak polarization and the corresponding peak angle as a function of the electron and photon energies, and best estimates of the polarization are given on the basis of the combined experimental and theroretical data. 
Geomagnetic disturbances and velocity of slow-drift solar radio bursts, M. G. Wood and C. S. Warwick, Nature 184, No. 4697, 1471 (1959).

Frequency drift rates were measured on records of the Fort Davis dynamic spectrum analyzer for 48 Type II (slow-drift) solar radio noise bursts. The change with frequency of the frequency drift rate is found to differ for two groups of bursts : those followed by geomagnetic disturbance and those followed by no disturbance. This change in drift rate is interpreted as acceleration of the radio source as it moves outward through the solar corona. Bursts followed by geomagnetic disturbance determine a rate that corresponds to greater positive acceleration of the source.

The outlook for machine translation, F. L. Alt, Proc. Western Joint Computer Conf., Volume 1\%, p. 203, San Francisco, Calif., (May 1960).

The current status of the major research projects concerned with the use of computing machines for the translation of natural languages (e.g., Russian to English) is surveyed. None of these projects has as yet reached the stage of fully automatic translation of satisfactory quality. The difficulties encountered fall into two main classes: semantic and syntactic. Several methods of approach have been used to overcome them; these are surveyed, and the approach of the National Bureau of Standards is described in more detail. It appears likely that within a few years automatic translation of fair quality may be possible, at a cost substantially below that of human translation. The major cost elements - initial development of machine programs, cost of machines and of operation - are analyzed in their dependence on the method of translation and on the type of equipment used.

Statistical evaluation of interlaboratory cement tests, J. R Crandall and R. L. Blaine, Am. Soc. Testing Materials Proc. 59, 1129 (1959).

A cooperative series of physical and chemical tests was made by 103 laboratories on twelve samples of cement during the period of one vear. Results of tests by all laboratories on each property were plotted in scatter-diagrams according to the Youden method to enable the participating laboratories to quickly evaluate their results. The results were treated statistically. Both statistical and graphic methods were employed to indicate the precision of the test methods and the extent of laboratory bias. The lack of precision with some of the tests indicated a need for improved test methods.

The work of each of the various laboratories was evaluated by a rating system. A large number of laboratories obtained results that were in good agreement but a few laboratories showed poor agreement with the larger group. Many of the discrepant laboratories did not improve during the one-year period the test program was active.

Discrepant results obtained by a few laboratories inflated appreciably the standard deviations among laboratories for the various tests.

The need for a continuing reference sample program was indicated.

Effect of notch geometry on tensile properties of annealed titanium at $100^{\circ}, 25^{\circ},-78^{\circ}$ and $-196^{\circ} \mathrm{C}, \mathrm{G}$. W. Geil and N. L. Carwile, Am. Soc. Testing Materials Proc. 59, 985 (1959). The combined effects of low temperatures and geometry of a circumferential notch on the tensile behavior of initially annealed commercially-pure titanium was investigated. The notch geometry was varied by changes in its depth and root radius; the notch depth, in terms of the cross-sectional area removed in machining the notch, ranged from 5 to 87 percent and the root radius ranged from 0.005 to 2.0 in. True stresstrue strain data were obtained to the initiation of the fracture of specimens at $100^{\circ}, 25^{\circ},-78^{\circ}$ and $-196^{\circ} \mathrm{C}$ and representative true stress-true strain curves are presented. The relationships of selected strength and ductility indices to the notch geometry and to the accompanying triaxialities and stress concentration factors are presented graphically and discussed in some detail in the text.
The wavefront reversing interferometer, J. B. Saunders, Colloquium on Optics and Metrology, Sponsored by the Intern, Commission of Optics, Brussels, Belgium, May 8-9, 1958. Publ. in Optics in Metrology, p. 227 (Pergamon Press, New York, N.Y., 1960).

The wavefront reversing interferometer is designed to test the shape of wavefronts. If a wavefront is characteristic of the shape of an optical element, or combination of elements, the evaluation of the wavefront is indirectly an evaluation of the element. It serves to measure the shapes of reflecting surfaces, the aberrations of lenses, and the variations of optical paths in a beam, such as inhomogeneity of the medium through which the light traveled. A unique method of analyzing the data is given. An instrument suitable for testing lenses and mirrors, by projecting the interference fringes onto a screen so that they may be observed by an audience, is described.

Spectra emitted from rare gas-oxygen solids during electron bombardment, L. J. Schoen and H. P. Broida, J. Chem. Phys. 32, No. 4, 1184 (1960).

Light emission from rare gas solids containing small amounts of oxygen has been excited by an electron bombardment technique. The Herzberg bands of oxygen and a line group believed to be the ${ }^{1} S \rightarrow^{1} D$ transition of the neutral oxygen atom form the strongest features of the observed spectra. In a neon matrix, the Second Negative system of $\mathrm{O}_{2}+$ has been identified. The effect of the various solids on the vibrational structure of the Herzberg bands is discussed.

Accurate microwave wavemeters with convenient calibration tables, H. E Bussey and A. J. Estin, Rev. Sci. Instr. 31, $410(1960)$

Accurate and convenient microwave cavity wavemeters are described that are suitable for many precise physical measurements. High Q's were attained by refined construction techniques. At $9000 \mathrm{Mc}$ a precision of $0.02 \mathrm{Mc}$ was obtained. The absolute accuracy also may be very high after strains in the metal have stabilized. A calibration table containing $10^{4}$ entries, easily formed by means of a high speed computer, makes the wavemeters convenient to use. The curve fitting method, accurate to one in $10^{6}$, is described.

The Stokes flow problem for a class of axially symmetric bodies, L. E. Payne and W. H. Pell, J. Fluid Mech. $\boldsymbol{7}, \mathrm{Pt}$. 4, $529(1960)$

The Stokes flow problem is concerned with fluid motion about an obstacle when the motion is such that inertial effects can be neglected. This problem is considered here for the case in which the obstacle (or configuration of obstacles) has an axis of symmetry, and the flow at distant points is uniform and parallel to this axis. The differential equation for the stream function $\psi$ then assumes the form $L^{2}-1 \psi=0$, where $L_{-1}$ is the operator which occurs in axially symmetric flows of the incompressible ideal fluid. This is a particular case of the fundamental operator of A. Weinstein's generalized axially symmetric potential theory. Using the results of this theory and theorems regarding representations of the solutions of repeated operator equations, the authors (1) give a general expression for the drag of an axially symmetric configuration in Stokes flow, and (2) indicate a procedure for the determination of the stream function. The stream function is found for the particular case of the lens-shaped body.

Explicit calculation of the drag is difficult for the general lens, without recourse to numerical procedures, but is relatively easy in the case of the hemispherical cup. As examples illustrative of their procedures, the authors briefly consider three Stokes flow problems whose solutions have been given previously.

Analysis of two-factor classifications with respect to life tests, M. Zelen, Book, Contributions to Probability and Statistics, Paper 42, p. 508 (Stanford Univ. Press, Stanford, Calif., 1960). Recently, much attention has been given to a study of the exponential distribution with particular emphasis on applications in life testing, e.g., Epstein and Sobel, Gupta, and Sobel. These papers have mainly considered techniques and procedures associated with observations from a single ex- 
ponential distribution. This paper outlines procedures to be used for analyzing the results of a two-way classification with respect to the scale factor of the exponential distribution. The test procedures are based on likelihood ratio tests and have their analogs in the usual analysis-of-variance tests for main effects and interactions. Approximations are given for tests based on small samples. These same procedures carry over directly to a two-way analysis of variance, if the quantities to be analyzed are variance estimates following chisquare distributions.

Microwave spectrum of trans-crotononitrile, V. W. Laurie, J. Chem. Phys. 32, No. 5, 1588 (1960).

The microwave spectrum of ethyl cyanide has been studied in the region from $17-36 \mathrm{kMc}$. Both parallel and perpendicular transitions have been assigned. Rotational constants (Mc) for the ground vibrational state are $a_{0}=27663.30, b_{0}=$ 4714.14, $c_{0}=4235.14, \quad D_{J}=0.0035, D_{J K}=-0.0496$. From Stark effects the dipole moment is calculated to be $\mu a=3.78 \mathrm{D}$, $\mu b=1.38 D, \mu=4.02 D$. Hyperfine splittings lead to a value of $-3.3 \mathrm{Mc}$ for the quadrupole coupling of the $\mathrm{N}^{14}$ nucleus along the $a$ axis. Rotational transitions of molecules in several excited vibrational states have also been measured. A Coriolis interaction between the torsional mode and the in-plane CCN bend has been found and is discussed. Splittings of transitions of molecules in the first excited torsional state show that the barrier hindering internal rotation of the methyl group is $3.05 \mathrm{kcal} / \mathrm{mole}$.

Disk distribution of flares associated with certain radio bursts, C. Warwick, Proc. Symp. Physical Processes in the Sun-Earth Environment, July 20-21, 1959 (Ottawa, Defence Research Telecommunications Establishment), DRTE Pub. No. $1025, p .249(1960)$.

Flares associated in time with U-bursts and with slowdrift bursts have an unusual distribution over the solar disk that may be caused by a directive effect in the radio emission. Such an effect, making the observation of these radio bursts more probable from a source near the limb of the sun than from a source near the center, could arise in coupling processes either between plasma waves and electromagnetic radiation, or between the two modes of electromagnetic radiation.

\section{List of Titles}

\section{Journal of Research, Section 64A, No. 5, September-October} 1960. 70 cents.

Infrared spectrum of hydrobromic acid. E. K. Plyler. above abstracts.)

Determination of the value of the faraday with a silverperchloric acid coulometer. D. N. Craig, J. I. Hoffman, C. A. Law, and W. J. Hamer.

Systems silver iodide-sodium iodide and silver iodide-potassium iodide. G. Burley and H. E. Kissinger.

Conformations of the pyranoid sugars. III. Infrared absorption spectra of some acetylated aldopyranosides. R. S. Tipson and H. S. Isbell.

Dissociation constant of 4-aminopyridinium ion in water from $0^{\circ}$ to $50^{\circ} \mathrm{C}$ and related thermodynamic quantities. R. G. Bates and H. B. Hetzer.

Tritium-labeled compounds. VI. Alditols-1-t and alditols-2-t. H. L. Frush, H. S. Isbell, and A. J. Fatiadi.

\section{Journal of Research, 64A, No. 6, November-December 1960. 70 cents.}

The spectrum of singly ionized atomic iodine (I II). W. C. Martin and C. H. Corliss. (See above abstracts.) The third spectrum of gold (Au III). L. Iglesias. (See above abstracts.)

Tolerances for layer thicknesses in dielectric multilayer coatings and interference filters. K. D. Mielenz.

Note on particle velocity in collisions between liquid drops and solids. O. G. Engel. (See above abstracts.)

Resistance of white sapphire and hot-pressed alumina to collision with liquid drops. O. G. Engel.

Note on the thermal degradation of polytetrafluoroethylene as a first-order reaction. S. L. Madorsky and S. Straus.

Heat of formation of titanium trichloride. W. H. Johnson, A. A. Gilliland, and E. J. Prosen.
Heat of formation of decaborane. W. H. Johnson, M. V. Kilday, and E. J. Prosen.

Ultra low-conductivity water by electrophoretic ion exclusion. W. Haller and H. C. Duecker.

Spectrophotometric determination of the ionization constant of dimethylpicric acid (2,4,6-trinitro-3,5-xylenol) in water at $25^{\circ}$ C. M. M. Davis, M. Paabo, and R. A. Robinson.

Spectrophotometric determination of the ionization constant of 2,4,6-trinitro-m-cresol in water at $25^{\circ}$ C. M. M. Davis and M. Paabo.

Method for the separation of titanium, zirconium, iron, and aluminum from one another and for their subsequent determination. T. J. Murphy, W. S. Clabaugh, and R. Gilchrist.

Journal of Research, Section 64C, No. 4, October-December 1960. 75 cents.

Error analysis of a standard microwave phase shifter. G. E. Schafer and R. W. Beatty. (See above abstracts.)

A method of controlling the effect of resistance in the link circuit of the Thomson or Kelvin double bridge. D. Ramaley.

Automatic precise recording of temperature. G. S. Ross and H. D. Dixon.

Gimbal device to minimize the effects of off-center loading on balance pans. H. A. Bowman and L. B. Macurdy.

Response of microchemical balances to changes in relative humidity. H. E. Almer.

Chemical changes occurring during the weathering of two coating-grade asphalts. S. H. Greenfeld.

Characteristics of fifteen coating-grade asphalts. S. H. Greenfeld.

Journal of Research, Section 64D, No. 5, September-October 1960. 70 cents.

ELF electric fields from thunderstorms. A. D. Watt.

Field strength measurements in fresh water. G. S. Saran and G. Held

Electrical resistivity studies on the Athabasca Glacier, Alberta, Canada. G. V. Keller and F. C. Frischknecht. (See above abstracts.)

Amplitude distribution for radio signals reflected by meteor trails. A. D. Wheelon. (See above abstracts.)

Computation and measurement of the fading rate of moonreflected UHF signals. S. J. Fricker, R. P. Ingalls, W. C. Mason, M. L. Stone, and D. W. Swift. (See above abstracts.)

On the theory of wave propagation through a concentrically stratified troposphere with a smooth profile. H. Bremmer. (See above abstracts.)

Polarization and depression-angle dependence of radar terrain return. I. Katz and L. M. Spetner. (See above abstracts.)

Methods of predicting the atmospheric bending of radio rays. B. R. Bean, G. D. Thayer, and B. A. Cahoon. (See above abstracts.)

Loss in channel capacity resulting from starting delay in meteor-burst communication. G. R. Sugar.

Elementary considerations of the effects of multipath propagation in meteor-burst communication. G. R. Sugar, R. J. Carpenter, and G. R. Ochs.

Use of logarithmic frequency spacing in ionogram analysis. G. A. M. King. (See above abstracts.)

Guiding of whistlers in a homogeneous medium. R. L. Smith. (See above abstracts.)

Propagation of microwaves through a magneto-plasma, and a possible method for determining the electron velocity distributions. A. L. Cullon.

On electromagnetic radiation in magneto-ionic media. $\mathrm{H}$. Kogelnik.

Radiation and admittance of an insulated slotted-sphere antenna surrounded by a strongly ionized plasma sheath. J. W. Marini.

A contribution to the theory of corrugated guides. G. Piefke.

High-gain, very low side-lobe antenna with capability for beam slewing. A. C. Wilson.

Shielding of transient electromagnetic signals by a thin conducting sheet. N. R. Zitron. (See above abstracts.)

Cylindrical antenna theory. R. H. Duncan and F. A. Hinchey. (See above abstracts.) 
Journal of Research, Section 64D, No. 6, November-December 1960.75 cents.

URSI National Committee Report:

Commission 1. Radio Measurement Methods and Standards

Commission 2. Tropospheric Radio Propagation

Commission 3. Ionospheric Radio Propagation

Commission 4. Radio Noise of Terrestrial Origin

Commission 5. Radio Astronomy

Commission 6. Radio Waves and Circuits

Commission 7. Radio Electronics

Temperature-induced stresses in solids of elementary shape, L. H. Adams and R. M. Waxler, NBS Mono. 2 (1960) 25 cents.

Table of wavenumbers, 2000 A to 7000 A, C. D. Coleman, W. R. Bozman, and W. F. Meggers, NBS Mono. 3, Vol. I (1960) $\$ 6.00$.

Table of wavenumbers, 7000 A to $1000 \mu$, C. D. Coleman, W. R. Bozman, and W. F. Meggers, NBS Mono. 3, Vol. II (1960) $\$ 6.00$

Mercury barometers and manometers, W. G. Brombacher, D. P. Johnson, and J. L. Ross, NBS Mono. 8 (1960) 40 cents.

A method for the dynamic determination of the elastic, dielectric, and piezoelectric constants of quartz, S. A. Basri, NBS Mono. 9 (1960) 15 cents.

The "1958 $\mathrm{He}^{4}$ scale of temperature", H. Van Dijk, M. Durieux, J. R. Clement, J. K. Logan, and F. G. Brickwedde, NBS Mono. 10 (1960) 25 cents.

Mechanical properties of structural materials at low temperatures - A compilation from the literature, R. M McClintock and H. P. Gibbons, NBS Mono. 13 (1960) $\$ 1.50$.

Bibliography on molecular and crystal structure models, D. K. Smith, NBS Mono. 14 (1960) 15 cents.

Calibration of line standards of length and measuring tapes at the National Bureau of Standards, L. V. Judson, NBS Mono. 15 (1960) 15 cents (Supersedes Circular 572).

New description of thorium spectra, R. Zalubas, NBS Mono. 17 (1960) 65 cents.

Measurement of neutron flux and spectra for physical and biological applications, NBS Handb. 72 (1960) 35 cents.

Quarterly radio noise data-March, April, May 1959, W. Q. Crichlow, C. A. Samson, R. T. Disney, and M. A. Jenkins, NBS Tech. Note 18-2 (PB151377-2) (1960) \$1.00.

Experimental plating of gun bores to retard erosion, V. A Lamb and J. P. Young, NBS Tech. Note 46 (PB151405) (1960) $\$ 2.50$

Report on the IGY oblique-incidence sporadic-E and Fscatter program, J. W. Finney and E. K. Smith, Jr., NBS Tech. Note 48 (PB151407) (1960) $\$ 2.50$

Isotopic abundance ratios reported for reference samples stocked by the National Bureau of Standards, F. L. Mohler, NBS Tech. Note 51 (PB161552) (1960) 50 cents.

Field strength calculations for ELF radio waves, J. R. Wait and N. F. Carter, NBS Tech. Note 52 (PB161553) (1960) 50 cents.

A bibliography of the physical equilibria and related properties of some cryogenic systems, T. M. Flynn, NBS Tech. Note 56 (PB161557) (1960) \$1.75.

Variable capacitor calibration with an inductive voltage divider bridge, T. L. Zapf, NBS Tech. Note 57 (PB161558) (1960) 50 cents.

A survey and bibliography of recent research in the propagation of VLF radio waves, J. R. Wait, NBS Tech. Note 58 (PB161559) (1960) 75 cents.

Measurements and standards in plasma-physics and astrophysics at the National Bureau of Standards, NBS Tech. Note 59 (PB161560) (1960) $\$ 1.00$

Proceedings of the 1960 conference on the propagation of ELF radio waves, NBS Tech. Note 61 (PB161562) (1960) 75 cents.

The linear viscoelastic behavior of rubberlike polymers and its molecular interpretation, R. S. Marvin. Book, Viscoelasticity: Phenomenological aspects, p. 27 (Academic Press, New York, N.Y.) (1960).
Low-frequency solar bursts and noise storms, A. Boischot R. H. Lee, J. W. Warwick, Astrophys. J. 131, No. 1, 61 (1960).

Magnetic properties of polycrystalline materials, D. M. Grimes, R. D. Harrington, and A. L. Rasmussen, J. Phys. Chem. Solids 12, 28 (1959).

Low-angle X-ray diffraction of fibrous polyethylene, A. S. Posner, L. Mandelkern, C. R. Worthington, and A. F. Diorio, J. Appl. Phys. 31, No. 3, 536 (1960).

The source-function in a non-equilibrium atmosphere. IV. Evaluation and application of the net-radiative-bracket R. N. Thomas, Astrophys. J. 131, 429 (1960).

Mass spectrometry, V. H. Dibeler and R. M. Reese, Anal. Chem. 32, No. 5, 211 (1960).

The melting temperature of natural rubber networks, D. E. Roberts and L. Mandelkern, J. Am. Chem. Soc. 82, 5, 1091 (1960).

Ionic charges of glass surfaces and other materials, and their possible role in the coagulation of blood, D. Hubbard and G. L. Lucas, J. Appl. Physiol. 15, No. 2, 265 (1960).

Mechanical and electromechanical properties of indium antimonide, R. F. Potter, J. H. Wasilik, and R. B. Flippen, Chapter 12 of the book, Mechanical Properties of Intermetallic Compounds, p. 265 (John Wiley and Sons, Inc., New York, N.Y.) (1960).

Electrometric pH determination, R. G. Bates, Chimia 14, 111 (1960).

Measurement of radiation exposure at the walls of medical $\mathrm{X}$-ray rooms for determining protective barrier requirements, S. W. Smith and J. R. Brooks, ATOMPRAXIS 6, No. 3, 77 (1960).

Theory of the magnetic and spectroscopic properties of neptunium hexafluoride, J. C. Eisenstein and M. H. L. Pryce, Proc. Roy. Soc. A255, 181 (1960).

Some fundamentals of modern dimensional metrology, I. H. Fullmer, Am. Soc. Tool \& Mfgr. Engrs. Tech. Paper 240, Book 1, 60, 1 (1960).

High pressure form of analcite and free energy change with pressure of analcite reactions, H. S. Yoder, Jr., and C. E. Weir, Am. J. Sci. 258-A, 420 (1960)

Class of nonlinear dielectric materials, P. H. Fang, R. S. Roth, and H. Johnson, J. Am. Ceram. Soc. 43, No. 3, 169 (1960).

The use of $2,2,4,4,6,8,8$-heptamethylnonane as a primary diesel fuel, T. W. Mears, R. M. David, and F. L. Howard, ASTM Bul. No. 245 , p. 75 (1960).

Sinn und bedeutung der strahlenschutznormen, L. S. Taylor, Rontgen-Blatter XIII, Heft 2, 33 (1960).

Chemically induced vibrational excitation: hydroxyl radical emission in the 1-3 micron region produced by the $\mathrm{H}+\mathrm{O}_{3}$ atomic flame, D. Garvin, H. P. Broida, and H. J. Kostkowski, J. Chem. Phys. 32, No. 3, 880 (1960).

Thermoelectric effects, H. P. R. Frederikse and W. W. Scanlon, Chapter 7.6 of the book, Methods of Experimental Physics, Vol. VI, p. 114 (Academic Press, Inc., New York, N.Y.) (1959)

Photographs of the high-altitude nuclear explosion "Teak," W. R. Steiger and S. Matsushita, J. Geophys. Research 65, No. 2, 545 (1960).

Appraisal of Land's work on two-primary color projections, D. B. Judd, J. Opt. Soc. Am. 50, No. 3, 254 (1960).

Further evidence of a solar corpuscular influence on large-scale circulation at $300 \mathrm{Mb}, \mathrm{N}$. J. MacDonald and W. O. Roberts, J. Geophys. Research 65, No. 2, 529 (1960).

Method for measurement of $\mathrm{E}^{\prime} / \mathrm{I}^{\prime}$ in the reciprocity calibration of condenser microphones, W. Koidan, J. Acoust. Soc. Am. 32, No. 5, 611 (1960).

Microphone diaphragm null method for sound pressure measurements, W. Koidan, J. Acoust. Soc. Am. 32, No. 4, 505 (1960).

An evaluation of a cesium beam frequency standard, R. C. Mockler, R. E. Beehler, J. A. Barnes, Symp. Quantum Electronics-Resonance Phenomena, p. 127 (Columbia University Press, New York, N.Y.) (1960).

Nonresonant absorption in symmetric-top gases: Dependence of relaxation frequency on temperature, A. A. Maryott, A. Estin, and G. Birnbaum, J. Chem. Phys. 32, No. 5, $1501(1960)$ 
The influence of lowered permissible dose levels on atomic energy operations in the United States, L. S. Taylor, Progr. in Nuclear Energy 1, 10 (1960).

Optimum antenna height for ionospheric scatter communication, R. G. Merril, IRE Trans. on Communs. Systems CS-8, 14 (1960).

Forced mixing in boundary layers, G. B. Schubauer and W. G. Spangenberg, J. Fluid Mech. 8, No. 1, 10 (1960).

X-ray attenuation coefficients from 13 to 80 Mev for hydrogen, carbon, water, and aluminum, J. N. Wyckoff and H. W. Koch, Phys. Rev. 117, No. 5, 1261 (1960).

Guiding of electromagnetic waves by uniformly rough surfaces-Part II, J. R. Wait, IRE Trans. Ant. Prop. APy, S163 (1959).

Electron impact study of the cyanogen halides, J. T. Herron and V. H. Dibeler, J. Am. Chem. Soc. 82, 1555 (1960).

Measured distributions of the instantaneous envelope amplitude and instantaneous frequency of carriers plus thermal and atmospheric noise, A. D. Watt and R. W. Plush. In Statistical methods of radio wave propagation: Proc. of a symp. University of California, Los Angeles, June 18-20, 1958, p. 233 (Pergamon Press, New York, N. Y.) (1960).

Interpretation of some features of low-frequency ionograms, J. M. Watts, J. Atmospheric and Terrest. Phys. 15, 73 (1959).

Electron detachment from the negative hydrogen ion by electron impact, S. Geltman, Proc. Phys. Soc. (London, England) LXXV, p. 67 (1960).

Transactions of the Joint Commission for Spectroscopy, Minutes of the Moscow Meeting, August 12-15, 1958 (Abridged), J. Opt. Soc. Am. 50, No. 4, 396 (1960).

"Ionization" of the hydrogen negative ion, S. Geltman, Proc. 4th Internatl. Conf. on Ionization Phenomena in Gases (North Holland Publishing Co., Amsterdam, The Netherlands), Uppsala 17-21, p. IA 19 (1960).

Cryogenic piping system design and installation, R. B. Jacobs, Heating, Piping and Air Conditioning, p. 143 (1960).

The nova outburst. V. The temperature and radius of the central exciting star and observation of elements other than hydrogen, S. Pottasch, Ann. Astrophys. J. 22, No. 4, 412 (Sept.-Oct. 1959).

Plan for the self-qualification of laboratories, A. T. McPherson, ASTM Bull. No. 246, 17 (1960).

Cosmic examples of heat conduction in very rare rotating or expanding gases, S. Chapman, Ann. Geophys. 15, 434 (Oct.-Dec. 1959)

The structure of $0,0^{\prime}$-diethyl methylphosphonothioate and conjugative properties of the $\mathrm{P}=\mathrm{S}$ bond, H. Finegold, J. Am. Chem. Soc. 82, No. 10, 2641 (1960)

How the method of rating the cooling load for refrigerated trailers has been standardized, P. R. Achenbach, C. W Phillips, and W. F. Goddard, Am. Soc. Heating, Refgr. Air Cond. Engrs. J. 2, No. 5, 45 (1960).

Analysis of methyl methacrylate copolymers by gas chromatography, J. Strassburger, G. M. Brauer, M. Tryon, and A. F. Forziati, Anal. Chem. 32, No. 4, 454 (1960).

Normal modes of a lattice of oscillators with many resonances and dipolar coupling, U. Fano, Phys. Rev. 118, No. 2, 451 (1960).

Calibration for carrier operated microphones and other reversible transducers, M. D. Burkhard, E. L. R. Corliss, W. Koidan, and F. Biagi, J. Acoust. Soc. Am. 32, No. 4, $501(1960)$.

Detection and estimation of low concentrations of aldehyde in air, E. E. Hughes and S. G. Lias, Anal. Chem. 32, No. 6, 707 (1960).

Magnetoresistive effects in indium antimonide and indium arsenide, H. P. R. Frederikse and W. W. Hosler, Vol. 2, Pt. 2, of the book, Solid State Physics in Electronics and Telecommunications, p. 651 (Academic Press, New York, N. Y.) (1960).

The NBS meteor burst communication system, R. J. Carpenter and G. R. Ochs, IRE Trans. Communs. System CS- $\boldsymbol{7}, 263(1959)$.

Characteristic energy losses of electrons, L. Marton, L. B. Leder, C. Marton, and M. D. Wagner, Proc. 4th Internatl. Conf. on Electron Microscopy, September 1958, p. 281 (Berlin, Germany) (1960).
Guiding of electromagnetic waves by uniformly rough surfaces-Part I, J. R. Wait, IRE Trans. Ant. Prop. APy, S154 (1959).

Radiation patterns of finite-size corner-reflector antennas, A. C. Wilson and H. V. Cottony, IRE Trans. on Ant. Prop. AP-8, 144 (1960).

Kinetics of the transport of water through silicate glasses at ambient temperatures, W. Haller, Phys. Chem. of Glass 1, 46 (1960)

Flow and stress near an interface between stratified liquids, K. Lofquist, Phys. of Fluids 3, No. 2, 158 (March-April 1960).

Heat sink method for measuring the cooling loads of refrigerated structures, P. R. Achenbach and C. W. Phillips, Proc. 10th International Congress of Refrigeration, August 1959, Copenhagen, Denmark (1959).

A technique for gripping high-strength fabrics during physical tests, K. F. Plitt and L. A. Dunlap, ASTM Bull. No. 246, 33 (1960).

Heated cell for quantitative infrared spectrophotometry, F. J. Linnig and J. E. Stewart, Anal. Chem. 32, 891 (1960). An analysis of an absolute torsional pendulum viscometer, E. A. Kearsley, Trans. Soc. Rheology III, 69 (1959).

The Black void reactor concept, C. O. Muehlhause, Nuclear Sci. and Engr. 8, No. 6, 505 (1960).

Dewar system for low temperature experiments, C. T. Zahn, Rev. Sci. Instr. 31, No. 3, 328 (1960).

Radio echoes from field-aligned ionization above the magnetic equator and their resemblance to auroral echoes, K. L. Bowles, R. Cohen, G. R. Ochs, and B. B. Balsley, Letter J. Geophys. Research 65, 1853 (1960).

Measurement on the smoothness of paper, T. W. Lashof and M. Mandel, Tappi 43, No. 5, 385 (1960).

Geomagnetic and solar data, J. V. Lincoln, J. Geophys. Research 65, 1639 (1960); J. Geophys. Research 65, 1821 (1960).

The spark of originality, A. T. McPherson, The Chemist 37, No. 7, 275 (1960).

Infrared emission spectra of gaseous $\mathrm{B}_{2} \mathrm{O}_{3}$ and $\mathrm{B}_{2} \mathrm{O}_{2}$, D. White, D. E. Mann, P. N. Walsh, and A. Sommer, J. Chem. Phys. 32, No. 2, $481(1960)$

A demonstration of color perception with abridged colorprojection systems, C. S. McCamy, Photographic Sci. and Engr. 4, No. 3, 155 (1960).

Heat of formation of nitrogen trifluoride and the $\mathrm{N}-\mathrm{F}$ bond energy, G. T. Armstrong, S. Marantz, and C. F. Coyle, Commun. to Editor, J. Am. Chem. Soc. 81, 3798 (1959).

Elastic constants of synthetic single crystal corundum at room temperature, J. B. Wachtman, W. E. Tefft, D. G. Lam, R. P. Stinchfield, J. Am. Ceram. Soc. 43, No. 6, 334 (1960).

A simple centering jig and goniometer for punching or drilling spheres for structural models, D. K. Smith, Am. Mineralogist 45, No. 5-6, 273 (1960).

Propagation of electromagnetic pulses in a homogeneous conducting earth, J. R. Wait, Appl. Sci. Research B8, 213 (1960).

Shielded coaxial leads for low temperature electrical measurements, N. L. Brown and R. N. Barfield, Rev. Sci. Instr. 31, No. 5, 517 (1960).

Rapid impact loading of textile yarms, J. C. Smith. Book, High Speed Testing, Vol. 1, p. 67 (Interscience Pub. Inc., New York, N.Y.) (1960).

The absolute zenith intensity of [OI] 5577 at College, Alaska, F. E. Roach and M. H. Rees, J. Geophys. Research 65, 1489 (1960).

Studies on sudden commencements of geomagnetic storms using IGY data from United States stations, S. Matsushita, J. Geophys. Research 65, No. 5, 1423 (1960).

Photometric observations of the twilight glow [OI] 5577 and [OI] 6300, L. R. Megill, J. Atmospheric and Terrest. Phys. 1\%, 276 (1960).

Microwave spectrum and internal rotation of ethyl cyanide, V. W. Laurie, J. Chem. Phys. 31, No. 6, 1500 (1959).

A study of local geomagnetic influence on the [OI] 5577 nightglow emission at Fritz Peak, J. W. McCaully, F. E. Roach, and S. Matsushita, J. Geophys. Research 65, No. 5, 1499 (1960). 
Local standards laboratories, A. T. McPherson, Handbook of Electrical Measurements, 1960 ed., p. 72 (1960).

Infrared emission spectrum of gaseous $\mathrm{HBO}_{2}, \mathrm{D}$. White, D. E. Mann, P. N. Walsh, and A. Sommer, J. Chem. Phys. 32, No. 2, 488 (1960).

A further note on "sweepers," J. M. Watts, J. Atmospheric and Terrest. Phys. 18, 81 (1960).

Compressive properties of hard tooth tissues and some restorative materials, J. W. Stanford, K. V. Weigel, G. C. Paffenbarger, and W. T. Sweeney, J. Am. Dental Assoc. 60, No. 6, 746 (1960)

$\mathrm{OH}$ emission in the earth's atmosphere, D. M. Gates and E. Jones, Proc. 2d Natl, Infrared Information Symp. 4, 145 (1959).

Tropospheric fields and their long-term variability as reported by TASO, P. L. Rice, Proc. IRE 48, 1021 (1960).

On the power of some rank-order two-sample tests, J. R. Rosenblatt. Book, Contributions to Probability and Statistics, Paper 32, p. 358 (Stanford Univ. Press, Stanford, Calif.) (1960).

Effect of tensile properties of reinforcement on the flexural characteristics of beams, R. G. Mathey and D. Watstein, J. Am. Concrete Inst. 31, No. 12, 1253 (1960).
The ionization potential of fluorine, J. T. Herron and V. H. Dibeler, Jr. Chem. Phys. 32, No. 6, 1885 (1960).

The intensity of [OI] 5577 in the subauroral region as a function of magnetic activity, F. E. Roach, J. Geophys. Research 65, No. 5, 1495 (1960).

Valences of the elements in analytical procedures, J. I. Hoffman, Chem. Anal. 49, No. 1, 30 (1960).

A comparative study of absolute zenith intensities of [OI] 5577, F. E. Roach, J. W. McCaulley, E. Marovich, and C. M. Purdy, J. Geophys. Research 65, No. 5, 1503 (1960).

*Publications for which a price is indicated (except for Technical Notes) are available only from the Superintendent of Documents, U.S. Government Printing Office, Washington 25, D.C. (foreign postage, one-fourth additional). Technical Notes are available only from the Office of Technical Services, U.S. Department of Commerce, Washington 25, D.C. (Order by PB number.) Reprints from outside journals and the NBS Journal of Research may often be obtained directly from the authors. 